\section{Psychological Safety} Among Learners: When Connection Is More Than Just Communication

B ynum and Haque's commentary "Risky Business: Psychological Safety and the Risks of Learning Medicine" 1 underscores the importance of our finding ${ }^{2}$ (published in the same issue of the Journal of Graduate Medical Education) of the association between psychological safety and the clinical learning environment.

Since the publication of our article, we have (1) conducted additional analyses on new data from our institution's annual survey ${ }^{3}$ of physician residents at the Loma Linda University Health Education Consortium and its affiliated hospitals; (2) held a focus group of medical students and residents to assess their interactions with supervisors; and (3) reviewed the literature in medical education on interpersonal connections between team members and patients.

Our preliminary findings suggest that communication in clinical teaching settings should be understood within a broader construct of "connection" that includes not only psychological safety, but also domains of empathy, quality of feedback, educational alliance, subjective emotional experience, bias, and the presence or absence of harassment. We developed questions in these domains based on the literature review and the Accreditation Council for Graduate Medical Education interpersonal and communication skills competency. These were further refined by input from our focus groups. The questions that were most applicable to feeling connected versus disconnected will be used in further studies. The value of looking at how different domains influence one another is highlighted by a survey of 553 physician residents at Loma Linda University. For the 2015-2016 survey, we added 2 questions on burnout from the Maslach Burnout Inventory and found associations between elements of burnout (Kendall's tau $=0.415$; $P<.001 ; \mathrm{n}=55)$ and callousness toward others (Kendall's tau $=0.385 ; P<.001 ; \mathrm{N}=553$ ), and between burnout and overall satisfaction with the training program.

DOI: http://dx.doi.org/10.4300/JGME-D-17-00195.1
Psychological safety may seem difficult to achieve with the hierarchical nature of residency training. Health care organizations should emulate the aviation industry, which, despite being similarly hierarchical, has identified staff well-being as fundamental to its overall success in delivering safe service. ${ }^{4}$ In unsafe environments, learners' self-images supersede engagement in activities that potentially risk their professional status, but otherwise could significantly enhance personal growth and patient outcomes. Expanding our understanding of the communication domains of psychological safety, empathy, quality of feedback, educational alliance, subjective emotion, bias, and bullying may explain higher error rates for teams reporting higher levels of psychological safety, within an organizational context of approachable leadership and a commitment to quality improvement. $^{5}$

The benefits of better connections generally and psychological safety specifically are well recognized, driving learning and organizational success. ${ }^{6}$ Traumatic situations with patients have promoted student resilience, whereas stressful encounters with residents and attending physicians have fostered depression. ${ }^{7}$

With improved connections with their supervisors, trainees can feel empowered to acknowledge uncertainty and participate in process improvement. Faculty should role model and create environments that encourage communication, inclusiveness, innovation, and collaboration to solve problems-while developing empathy for learners' potential experiences with shame and low self-esteem.

More research is needed to explore what specific faculty behaviors and organizational changes can promote psychological safety and connections with learners.

Karina D. Torralba, MD, MACM

Chief and Fellowship Program Director, Division of Rheumatology, Loma Linda University

Staff Rheumatologist, VA Loma Linda Healthcare System

David Puder, MD

Assistant Professor, Department of Psychiatry, Loma Linda University

\section{References}

1. Bynum WE, Haque TM. Risky business: psychological safety and the risks of learning medicine. J Grad Med Educ. 2016;8(5):780-782. 
2. Torralba KD, Loo LK, Byrne JM, et al. Does psychological safety impact the clinical learning environment for resident physicians? Results from the VA's Learners' Perception Survey. J Grad Med Educ.

2016;8(5):699-707.

3. Byrne JM, Loo LK, Giang D. Monitoring and improving resident work environment across affiliated hospitals: a call for a national resident survey. Acad Med. 2009;84(2):199-205.

4. Kapur N, Parand A, Soukup T, et al. Aviation and healthcare: a comparative review with implications for patient safety. JRSM Open. 2016;7(1).
5. Edmondson AC. Learning from mistakes is easier said than done. Group and organizational influences on the detection and correction of human error. J Appl Behav Sci. 1996;32(1):5-28.

6. Hoff TJ, Pohl H, Bartfield J. Teaching but not learning: how medical residency programs handle errors. $J$ Organiz Behav. 2006;27(7):869-896.

7. Haglund ME, aan het Rot M, Cooper NS, et al. Resilience in the third year of medical school: a prospective study of the associations between stressful events occurring during clinical rotations and student well-being. Acad Med. 2009;84(2):258-268. 